\section{Autonomia ou dependência da ciência}

Tradução de Juremir Machado da Silva
EM CONSEQÜÊNCIA DO "caso Sokal"1, a questão de saber em que condições se pode falar de autonomia ou de dependência da ciência retomou toda a sua virulência e, cabe afirmar, toda a sua pertinência. Muitos viram na mistificação de Sokal um teste de falsificação científica: falsificar o enunciado de um discurso para testar os critérios de reconhecimento da sua validade. Mas parece mais divertido de ver nisso, antes de tudo, um jogo de cena entre dois poderes bastante distintos: os "científicos", de um lado, e os "narradores/literários", de outro. O caso pode então ser decomposto em dois episódios: um, molieresco, da comédia acima de tudo, e outro, torquemadesco, inquisitorial e delator.

Sokal conseguiu, com efeito, publicar um texto numa revista séria, no qual parodia um estilo pedante e afetado, misto das idéias de "desconstrução" e de "construtivismo"; a primeira consistiria na tendência a minar as bases clássicas do edifício majestoso das leis da natureza; o outro, o construtivismo, tentaria substituir essas leis impessoais por uma ideologia oriunda de condições sócio-históricas. Desmascarando a fraude "molieresca", Sokal conclui que falar da ciência, aquém do discurso científico, conduz à vaidade e à facilidade.

Daí o segundo aspecto, "torquemadesco", do caso. Este detonou uma grande ofensiva lançada pelos representantes instituídos da Ciência dita "dura" e "pura" (da qual Weinberg é um dos líderes). Estes pretenderam pois liquidar os estilos "construtivista" e "desconstrutivista" que poluem o discurso científico, além de proibir a Psicologia e a Sociologia de terem qualquer pretensão de dar conta da ciência; em resumo, eliminar toda pretensão epistemológica de "relativizar" a própria ciência e toda contestação da organização disciplinar; varrer tudo o que poderia atentar contra o mono- 
pólio do conhecimento pelos cientistas; em suma, sufocar qualquer veleidade fora da ciência de tratar das idéias científicas como objeto de reflexão ou como objeto filosófico.

Contudo, o problema da ciência como objeto de reflexão filosófica e epistemológica aparece mais do que nunca. De fato, a ciência enquanto tal é problemática, ou seja, gera por si mesma problema e leva a pensar. Em outras palavras, trata-se de uma instância paradigmaticamente complexa, forma privilegiada de racionalidade, mas que não integra o sujeito pensante. Ignora o observador - conceitualizador. Assim, a ciência não está somente desprovida de autoconsciência, mas é necessariamente separada da consciência ética. Eis o que lhe dá a sua autonomia, mas também o que estabelece, na época contemporânea, tendo desenvolvido poderes de manipulação e de morte, a sua insuficiência.

Husserl tentou mostrar como a "crise das ciências européias" exprime em profundidade a crise nascida da ocultação do sujeito que faz a ciência. Segundo ele, somente o retorno reflexivo à situação das ciências pode permitir a elucidação do sentido da crise que se manifesta até no campo político. A idéia fundamental de Husserl diz respeito ao desinteresse dos cientistas pela própria subjetividade que impregna os seus procedimentos, isto é, refere-se à falta de reflexividade das suas pesquisas. Em outros termos, os espíritos ditos "científicos" esvaziam a ciência dos seus próprios operadores e do seu contexto humano em benefício de uma forma lógica a priori capaz de permitir a conversão de todas as coisas, e do Homem, em algoritmos.

Ora, a questão que se deveria colocar ao sujeito da verdade científica é a seguinte: em que condições e através de quais observadores/conceitualizadores/construtores um teorema é verdadeiro ou uma coisa é científica? As leis, as descobertas, a objetividade assegurada por uma ciência, escapam às condições históricas, sociais e psicológicas em que surgem ou, ao contrário, são delas prisioneiras? Este problema foi considera- do na sociologia, há mais de meio século. Thomas Merton, por exemplo, vê os determinismos sociais e pergunta: como pode ser que a ciência, incapaz de fugir a essas determinações, produza um saber que as supera e transcende em razão do seu caráter universal e objetivo?

Parece evidente que a Terra não gira em torno do Sol até o momento em que Copérnico, em determinadas condições, singulares e precisas, estabelece a equação que prova o "heliocentrismo". No outro extremo, outra sociologia foi marcada pela forte personalidade do escocês Bloor, para quem a ciência pretende universalizar-se e elevarse acima do seu contexto sócio-histórico para melhor esconder de si mesma a sua função, a de ser uma "ideologia" de nossa sociedade. Se a isso se acrescenta uma pitada de marxismo (ou de pseudomarxismo), essa "ideologia" torna-se a do capitalismo contemporâneo.

O problema da autonomia da ciência coloca-se hoje, em conseqüência, de duas maneiras tão redutoras quanto antagônicas. Vê-se, por um lado, uma ciência reduzida à física tradicional e às suas leis que regem o Universo de forma imperial e incontestável e, por outro lado, retira-se da ciência qualquer privilégio epistemológico em relação a uma ideologia. A dificuldade reside então numa crítica simultânea desses dois pontos de vista.

Interessa-me reconhecer amplamente os componentes não-científicos e contudo necessários à constituição e à produção do saber científico. Quero também reconhecer a possível validade de todo estudo de contexto e o valor de estimulação de toda polêmica científica. Enfim, insisto em criticar a "relativização" generalizada. Nesse sentido, com efeito, o "reducionismo" sócio-histórico que tende a reduzir toda idéia, inclusive a idéia científica, às suas condições espaço-temporais de formação mina a sua própria base. Pois a idéia segundo a qual todo conhecimento depende das suas condições de emergência "relativiza-se" a si mesma. A idéia segundo a qual não existe 
verdade universal elimina a sua validade universal. Em conseqüência, a concepção que "relativiza" a ciência deve relativizar a si própria e pôr em suspenso qualquer pretensão à validade absoluta. Claro, tamanho problema não pode ser tratado de maneira simplificada. Antes de abordá-lo, exporei dois princípios ou pontos de vista.

\section{Primeiro princípio: autonomia-de- pendência}

Habitualmente a idéia de autonomia opõe-se à de dependência, assim como a noção de liberdade opõe-se à de determinismo. Na concepção científica tradicional, a autonomia não podia ser pensada, pois existiam determinações e causas exteriores, a não ser metafisicamente. Hoje, com o progresso das noções originárias da cibernética e da teoria dos sistemas, sobretudo com a concepção de auto-organização (em função do segundo princípio da termodinâmica), ficou claro que sistemas auto-organizadores ou autoprodutores gastam energia no próprio trabalho de auto-organização. Necessitam portanto captar energia no meio em que estão instalados. Abastecem-se também, como dizia Schrödinger, de ordem e de organização. Por exemplo, os animais e os vegetais comportam a organização da rotação da Terra, ou seja, a alternância do dia e da noite ou das estações, o que se observa na hibernação ou no despertar da natureza na primavera, ou, nas sociedades, através da implantação do calendário.

O paradoxo é o seguinte: um sistema só pode ser autônomo se depender de condições externas. Quanto mais dependemos de uma cultura, quanto mais lemos e aprendemos, mais conhecemos o mundo e as sociedades, e mais chances temos de desenvolver a autonomia do nosso espírito. De fato, este texto deveria chamar-se "Autonomia e dependência". Em resumo, a minha concepção de autonomia da ciência é a da auto-eco-re-organização.

\section{Segunde princípio: todo conhecimen- to, inclusive ๑ científico, nã॰ é ๑ reflex॰ ou ๑ espelh॰ d॰ mund॰ exterior.}

O conhecimento é sempre uma tradução e uma reconstrução. O próprio cérebro nunca se conecta diretamente com o mundo. Nossos terminais sensoriais sofrem influxos e estimulações traduzidos num código binário, trabalhados e transformados para finalmente dar-nos a percepção. Além disso, um conhecimento sob forma de idéias e de teorias é uma tradução e uma reconstrução. Por essa razão, as idéias servem-nos tanto para comunicar quanto para ocultar o mundo exterior. Nessa percepção, a ciência não é o perfeito reflexo da ordem majestosa da natureza, que revelaria, nem tampouco uma pura construção do espírito. Sou "co-construtivista": a ciência elabora-se com a cooperação do mundo exterior.

Ao entrar no cotidiano dos laboratórios, como fez Bruno Latour, encontra-se um mundo tipicamente humano, com relações de trabalho, de amizade, de hostilidade, de ciúme, de competição e de inveja. Os argumentos dos pesquisadores nem sempre se baseiam nos modos existentes de pura racionalidade. A "relativização" é portanto desejável desde que não se transforme numa redução onde o laboratório científico teria uma vida da mesma ordem que um gabinete de estudos publicitários ou um restaurante.

As grandes teorias científicas (não os dados nos quais se baseavam) do século XIX, da época triunfal da ciência clássica, foram praticamente todas abandonadas, hoje, à exceção da teoria da energia. Em certos casos, foram "relativizadas"; em outros, tornadas periféricas. A ciência não é uma concepção arquitetural que de patamar em patamar constrói um edifício majestoso. Os "postulados fundamentais" são hoje pontuais, parciais ou foram abandonados, embora parecessem antes verdades evidentes. Por exemplo, o determinismo, como foi es- 
tabelecido por Laplace, não cedeu lugar ao acaso ou ao risco. Deixou de ser universal, estabelecendo-se um estranho jogo entre, de um lado, um princípio de ordem comportando determinação, estabilidade, regularidade, ciclos e, de outro lado, um princípio de desordem com perturbações, colisões, riscos. O princípio de redução perde terreno na medida em que se descobre a sua insuficiência, pois ignora que a soma das qualidades dos elementos de um conjunto ou de um sistema não resulta no conhecimento do "todo". A organização desse "todo" produz emergências, isto é, certo número de qualidades irredutíveis à das parte isoladas, o que Pascal formulou assim: "Não posso conceber o conhecimento de um todo se não conheço as suas partes, nem conceber o conhecimento das partes se não conheço o todo".

O princípio de separação das disciplinas mostra cada vez mais os seus limites. Reorganizações polidisciplinares aparecem, como no caso das ciências da Terra, a partir de um sistema Terra complexo. A ecologia associa disciplinas derivadas das ciências físicas, da biologia, da botânica e da zoologia. Estruturam-se colaborações. É o caso na cosmologia, que associa a observação da astronomia com as experiências da microfísica e do acelerador de partículas; quanto à pré-história humana, diferentes disciplinas colaboram para conceber o processo de "hominização".

A ciência evolui. $\mathrm{O}$ aparecimento de uma contradição não é mais necessariamente o sinal de um erro de raciocínio, mas de que algo, na realidade, não é redutível à lógica clássica, aos seus axiomas de identidade e de não-contradição. No campo da lógica matemática, a própria dedução tem mostrado os seus limites. Está em curso uma mutação ou metamorfose da ciência, o que já aparecia na obra de Bachelard. Por outro lado, pensadores da ciência tão diferentes como Popper, Kuhn, Holton ou Lakatos estabeleceram que postulados indemonstráveis existiam nas teorias científicas e que os themata (conforme o termo de Hol- ton), idéias obsessivas a priori, animavam o espírito dos grandes cientistas. Assim é com o thema do determinismo em Albert Einstein e o da indeterminação em Niels Bohr. Kuhn revelou a existência dos paradigmas, ou seja, dos princípios ocultos que dirigem o saber e permitem organizá-lo. Esses paradigmas podem sofrer revoluções ou transformações. Depois, constatou-se no desenvolvimento da cosmofísica que as leis universais da natureza valiam apenas para o nosso universo singular, sendo leis singulares de um universo singular.

Ao examinar a ideologia que data de um ou dois séculos, exclamamos: "Que cegueira! Que erros!" O mesmo vale (Infelizmente? Ainda bem?) para a ciência do século passado. A maior cegueira considerava o Universo como uma máquina determinista trivial.

Esse universo "perfeito" não podia ser mais pobre; nenhuma invenção, nenhuma criação era possível. Evidentemente tornouse necessário concluir que o nosso universo era imperfeito. A noção de universo "perfeito" era contudo admitida como dogma por grandes espíritos, assim como a ocultação dos conjuntos, dos sistemas e das emergências era aceita por quase todos.

A eliminação metódica do que não pode ser quantificado leva à idéia de que o único real interessante é o quantificável. "O Livro da natureza está escrito em linguagem matemática", dizia Galileu. Idéia justa se pensamos que a matemática permite ler a ordem e a organização dos fenômenos naturais. Redutora se elimina o que não pode ser quantificado. A tentativa de fazer ciências humanas conforme esse modelo determinista, mecanicista e quantificado, eliminando os sujeitos, o risco e a desordem, corresponde a essa mesma ótica.

Felizmente nosso século conheceu duas evoluções científicas. A primeira, com a termodinâmica, a microfísica e a astrofísica, atingiu a física, introduzindo a incerteza e a desordem, levando a considerar as dialógicas entre ordem e desordem. A segunda, com as ciências sistêmicas, que associam 
disciplinas como a ecologia, as ciências da Terra e a cosmologia, é mais recente, datando dos anos 50. A evolução produziu-se no sentido da complexidade. Atingimos idéias mais pertinentes na medida em que perdemos uma visão mutiladora, unidimensional ou redutora. Ao examinar a história das ciências do século XVII ao XX, percebe-se que não se trata de um edifício construído segundo o projeto de um arquiteto genial, mas de um canteiro tumultuado, eternamente em obras.

Existiu o mito de que a ciência, ao contrário da religião, trazia a certeza. Contudo, Whitehead constatou que a ciência muda bem mais do que a religião, que apresenta a certeza absoluta, a da revelação divina. A ciência alimenta-se incessantemente de elementos novos, de novas idéias, de novos conhecimentos que conduzem à mudança. Havia também o mito de que a missão da ciência só poderia ser benéfica. Era a época das grandes odes ao progresso como a que foi escrita por Renan em $O$ Futuro das ciências. Hoje, percebemos que a ciência desenvolve poderes utilizáveis num sentido de benfeitoria como num sentido destruidor ou manipulador.

\section{Outro mito fa-}

zia do rigor uma propriedade do espírito dos cientistas, especialmente dos físicos. Ora, Popper atribui o rigor dos físicos às severas restrições exercidas nos laboratórios de física, não ao espírito dos físicos. Os biólogos trabalham num meio mais complexo, com menos restrições, e os sociólogos quase não as enfrentam, daí a falta de rigor que os caracteriza. Mas o físico não carrega o seu rigor para fora do laboratório. Físicos geniais, grandes ganhadores do Nobel, viram na URSS um paraíso dos trabalhadores ou uma sociedade igualitária... Transpor a realidade do laboratório para a realidade social movediça e complexa conduz a erros ou mesmo à inépcia. Em relação a isso a distinção entre espíritos superiores, os cientistas puros, e os espíritos mais vulgares, os cidadãos, não tem mais sentido.

A ciência arrastava também o mito da conquista da natureza. A idéia de que o uso da ciência deve ajudar o ser humano a tornar-se mestre e possessor da natureza foi formulada por Bacon, Descartes, Buffon, Marx. A natureza era percebida como um universo de objetos feitos para serem conquistados e manipulados. Essa idéia dava ao Homem acsuldostância divina: ele substituía Deus e torna-
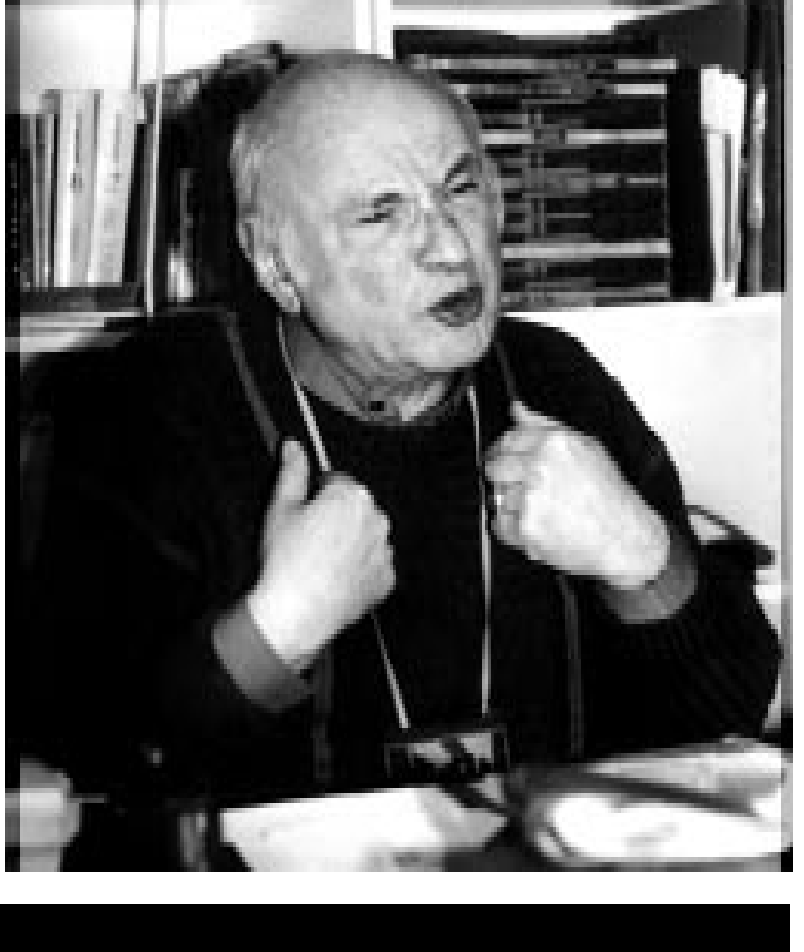
va-se o soberano do mundo... A noção de conquista da natureza tornou-se ridícula desde que se mediu a insignificância de nossa situação: a Terra, minúsculo planeta girando em torno do nosso medíocre Sol, situada numa galáxia periférica. Além disso, de tanto querer conquistar e dominar a Terra de maneira incontrolada, criamos as condições de destruição da nossa própria vida.

Deve-se considerar em conjunto essas duas verdades contrárias. Eis o que chamo de dialógica. A ciência possui ao mesmo tempo um poder de cegueira e um fantástico poder de elucidação. Nenhum filósofo poderia ter imaginado descobertas tão fabulosas e inesperadas quanto a do Cosmos e da microfísica. A própria vida é extraordinária quando se pensa que uma bactéria é uma organização mais complexa que o 
conjunto das usinas do Ruhr. Todas essas descobertas substituem as banalidades, as evidências e as idéias simples por noções complexas, enigmas ou mistérios surpreendentes.

Hoje, nosso conhecimento encontra-se incompleto. Novas revoluções científicas acontecerão, sem dúvida, mas não conseguiremos descobrir a pedra fundamental e última do Universo ou a lei geral e unificadora. Não haverá retrocesso.

Houve concordância entre o desenvolvimento da Europa ocidental, com base na sua potência, na sua indústria e nas suas sociedades, e o da ciência clássica desabrochando através da experimentação dos poderes de manipulação e de dominação da natureza. Um vínculo forte, cada vez mais desenvolvido, estabeleceu-se entre a ciência e a técnica. A técnica utiliza a ciência como meio para manipular, mas a ciência utiliza a manipulação como meio para conhecer. Uma espécie de máquina ligada ao formidável desenvolvimento do poder e da hegemonia ocidentais entrou em ação: a "tecnociência". A crise histórica enfrentada pela Europa ocidental vincula-se à crise da ciência clássica e à descoberta da complexidade.

Como conceber a autonomia da ciência? A história da ciência pode ser feita por "endogenistas", que concebem a história como um processo autônomo sui generis, e por "exogenistas", que a consideram como determinada pelos acontecimentos sociais, econômicos, políticos... Em minha concepção de auto-eco-produção, fui levado a vincular dialogicamente essas duas idéias aparentemente contraditórias, mas que considero complementares. A autonomia é um desenvolvimento endógeno que necessita de condições exteriores, ou seja, de um desenvolvimento endo-exógeno.

\section{Como atingir a autonomia da ciên- cia?}

Um critério de autonomização foi a disjunção entre a ciência, a ética e a política. A ciência dizia: “Os juízos de fato, os dados ou o saber me interessam, mas não as conseqüências morais ou políticas". Em aparência, significava retirar-se do vastíssimo domínio da moral e da política. À época em que a ciência se autonomiza, nos séculos XVII e XVIII, ela não adquire os formidáveis poderes que tem hoje. A sua autonomia em relação à ética e à política foi portanto salutar e necessária.

A organização interna da ciência foi a segunda fonte da sua autonomia: o complexus entre o consenso e o conflito. A ciência funciona com base em dois registros: necessidade de consenso e necessidade de conflito. $O$ consenso faz parte necessariamente do princípio do respeito dos dados objetivos e do valor do conhecimento pelo conhecimento, sejam quais forem as conse-qüências filosóficas, morais ou políticas. Por outro lado, desde que observadores ou experimentadores, muitos diferentes em função de idéias ou de nacionalidade, concordam a respeito de uma observação, de uma experiência ou de uma teoria, estabelece-se o consenso. Em contrapartida, a ciência progride através do conflito de teorias, que não são apenas oposições de construções racionais aplicadas ao real, mas também confrontos entre postulados, themata, paradigmas. Estes formam a parte não científica indispensável ao conhecimento científico.

A máquina científica funciona um pouco como a democracia. Não foi por acaso que a instituição filosófica nasceu ao mesmo tempo que a democracia ateniense. Mas ela não possui os meios para estabelecer um consenso e o debate continua sempre aberto. Ao contrário, a ciência procede por experimentação-verificação. Todavia a analogia é profunda. Uma democracia necessita de um consenso. Os cidadãos decidem de abster-se de resolver os seus problemas aos socos ou a punhaladas e os conflitos passam a ser regulados através da argumentação na Ágora, no fórum ou nos meet-ings eleitorais, sendo sancionados por eleições. A democracia não tem verdade e 
deixa as diferentes verdades oporem-se; a vitoriosa, por um tempo, instala-se no poder. A ciência também não tem verdade. Toda tentativa de impor uma verdade do exterior, como ocorreu com o nazismo ou com o stalinismo, fracassou.

A ciência é o espaço de conflito das verdades; a sua verdade consiste em permitir que as verdades se enfrentem. Esse sistema tem a sua própria vitalidade, sendo regulado pelo consenso e alimentado pelo conflito, tirando daí a sua autonomia.

O "complexo quadrúpede" é outro elemento de autonomia. A ciência anda de quatro "patas": empirismo, racionalismo, imaginação e verificação. Alguns cientistas, como Albert Einstein, são mais racionalistas; outros, mais empíricos, interessandose mais pelos fatos; outros ainda são mais imaginativos ou verificadores. Essas quatro "patas" complementam-se mesmo entrando, ocasionalmente, em conflito. Há, em permanência, conflito, do qual se alimenta a vitalidade da ciência, entre o racionalismo e o empirismo.

Em todas as sociedades, conhecimento empírico e elementos científicos são disseminados no conjunto dos conhecimentos. Mas a contribuição da história européia consiste na autonomização relativa da ciência na sociedade, o que se produz depois do Renascimento, num período de extraordinária "problematização" do mundo. A partir do século XVII, um ramo particular - a ciência - separa-se da filosofia. Esse ramo tira a sua ratificação da prova ou da refutação. A ciência autonomiza-se sem parar através da permanente regeneração desse processo. Para gerar objetividade, necessitase da "intersubjetividade". A "problematização" deve ser permanentemente revitalizada ou então tudo se bloqueia. A objetividade retroage, retoma as suas condições de formação e assim recupera a sua vitalidade. Trata-se de um circuito autoprodutor cujos produtos e efeitos são necessários à causa e à produção.

A ciência autoproduz-se e não o faz em circuito fechado, mas em condições históricas precisas: o Renascimento, o nascimento do mundo ocidental, o desenvolvimento e a difusão da civilização ocidental. A autonomia da ciência é portanto inseparável de um processo de regeneração permanente que não parou de funcionar desde o século XVIII, apesar do endurecimento, dos dogmas, dos juízos de autoridade, das exclusões, das quase excomunhões e da hiperespecialização. Processo que só poderia ser bloqueado do exterior se todos os laboratórios fossem fechados e a atividade científica proibida. Ainda que a ciência seja filha da livre discussão, os regimes totalitários sufocaram alguns dos seus ramos, favorecendo aqueles que permitiram construir bombas atômicas. Mas o processo científico tornou-se de tal modo autônomo que ficou insensível às variações políticas. Condições exteriores drásticas podem bloqueá-lo, mas ele sempre se regenera. Porém toda teoria tende ao dogmatismo e toda idéia tende a solidificar-se depois de admitidas, pois é muito difícil impor uma idéia nova, a qual, em geral, parece absurda e desviante.

Apesar de tudo, as teorias científicas permanecem teorias, ou seja, permanecem abertas a dados externos e a argumentos contrários, em oposição às doutrinas que são fechadas e passam o tempo a autojustificar-se com base no pensamento do genial fundador. Uma teoria científica não se justifica com afirmações repetidas do tipo "como disse Marx" ou "como disse Freud"... As teorias científicas são por princípio abertas, tendo por virtude o fato de serem biodegradáveis e não a imortalidade como se acreditava no século XIX.

\section{Conclusão}

Como Joseph Prudhomme se servia do sabre para defender as instituições e, caso necessário, combatê-las, defendo a ciência mesmo combatendo-as. Essa é a única posição que me parece suportável.

Não se deve temer as investigações sobre as condições históricas, sociológicas, 
econômicas, técnicas e psicológicas dos processos científicos; e a parte não científica necessária à ciência deve ser reconhecida. A tendência à mitificação e à sacralização da ciência deve ser combatida, mas esta não pode ser reduzida a uma ideologia entre outras. Certo, a ciência secretou ideologia em determinadas condições históricas e poderá fazê-lo novamente. Gerou também cegueira e, ao mesmo tempo, elucidação; assim, não contém o saber absoluto. Deve-se também resistir à contra-reforma cada vez que casos do tipo Sokal tentam restaurar uma esfera superior, pelo rigor, pela razão e pela verdade que supostamente esta possui. Essa esfera superior da ciência, indissociavelmente ligada à organização disciplinar tradicional, seria, claro, inacessível aos profanos. Tal pretensão não é razoável como ilustra o exemplo de Popper a propósito do rigor dos físicos.

A ciência conhece processos de racionalização ainda que estes sejam combatidos. Com efeito, a idéia de que a ciência poderá explicar tudo é racionalizadora e delirante. Sempre haverá uma parte de enigma e de não-racionalizável no Universo. Verdades científicas existem, mas todas situadas num tempo e num espaço dados. A Terra gira em torno do Sol a uma velocidade determinada, mas essa rotação, esse movimento e essa velocidade eram certamente diferentes há cem milhões de anos e o serão em cem milhões de anos, desaparecendo com a implosão ou explosão do Sol.

Enfim, existe o problema do direito ao conhecimento. Os profanos não podem entrar nos laboratórios, manipular as provetas e os tubos de ensaio, nem entrar na sofisticação da formalização matemática... São incompetentes. Mas os problemas fundamentais das grandes teorias científicas e as idéias subjacentes podem ser partilhadas e não devem ser reservadas aos eruditos. Por exemplo, a termodinâmica é um campo extremamente esotérico, mas as suas idéias, especialmente o segundo princípio, são inteligíveis. Pesquisadores como Brillouin, Schrödinger ou Prigogine escreveram para partilhar esse conhecimento com os leitores. Entrar na física quântica é impossível. Em contrapartida, é possível saber que esse domínio escapa à lógica clássica ou ao aparente bom senso.

Todo cidadão necessita de uma visão de mundo. As sociedades tradicionais tinham uma visão cíclica e rotativa do mundo. Não podemos fugir ao que foi desenvolvido pela cosmofísica a partir dos anos 60. Hubert Reeves e outros astrofísicos fazem-nos partilhar as suas idéias e convicções sem destilar um bê-a-bá para crianças. Cientistas como Bernard d'Espagnat, JeanMare Lévy-Leblond e François Jacob desempenham o papel de humanistas e de filósofos, pois os filósofos não cumprem essa tarefa. "Eles escrevem para todos e para ninguém", dizia Nietzsche. Fazem-no para quem gostaria de ser "um homem de bem", como se falava no século XVII.

Hoje, os problemas fundamentais contra os quais se chocam os cidadãos encontram-se no progresso da ciência: para onde vamos, quem somos, o que é a realidade? Voltaremos a uma sociedade de castas com, de um lado, os "sacerdotes", como nos impérios teocráticos e no Egito faraônico, e, de outro lado, os construtores das pirâmides. Se estes dispõem de meios, especialmente da informática, um pouco mais sofisticados que os da época dos faraós, não "podem ainda compreender". O saber deve ser propriedade privada de uma corporação cercada por arame farpado?

A autonomia da ciência não está na pretensão dos altos dignitários e dos seus discípulos de escapar a qualquer crítica externa e a toda determinação social, mas no processo auto-eco-organizador que incessantemente se regenera.

É daí que a ciência tira as suas energias e ardores para a busca do verdadeiro e para a luta contra o dogmatismo. Bebe nos espíritos humanos e na cultura viva das sociedades .

\section{Nota}


1 Professor, reconhecido e respeitado, de Física em Nova York, Alan Sokal conseguiu, em 1996, publicar numa revista prestigiosa, Social Text, um artigo parodiando, sob forma científica, as teses da própria revista. Pretendia com isso 